\title{
Disjunction of natural concepts
}

\author{
JAMES A. HAMPTON \\ The City University, London, England
}

\begin{abstract}
Two experiments investigated the way in which the rated membership of items in disjunctively defined categories, such as FRUITS OR VEGETABLES and PETS OR FARMYARD ANIMALS, varies as a function of membership in individual constituent categories. Items were rated for category membership and typicality in each category separately, and in their disjunction. The results showed non-Boolean effects of both overextension and underextension of the disjunctions. Typicality in the disjunction was highly predictable from constituent typicality values, using regression equations with negative interaction terms. The results are compared with similar effects for concept conjunctions and are discussed in terms of an intensional model of conceptual combination (Hampton, 1987b, 1988).
\end{abstract}

The problem of conceptual combination concerns the way in which the meaning of a complex phrase can be related to the meanings of its constituent parts. In a number of recent articles, this research problem has been identified as playing a crucial role in the development of central theoretical questions about the nature of human knowledge and the concepts on which it depends (Cohen \& Murphy, 1984; Hampton, 1983, 1987b, 1988; Jones, 1982; Murphy, 1987; Osherson \& Smith, 1981, 1982; Smith \& Medin, 1981; Smith \& Osherson, 1984; Thagard, 1983; Zadeh, 1982). In particular, studies of concept conjunctions (Hampton, 1987b, 1988; Jones, 1982; Osherson \& Smith, 1981) have been used as evidence for (and against) the prototype theory of natural concepts (Rosch, 1978; Rosch \& Mervis, 1975), whereas the processes involved in adjectival modification of nouns (Murphy, 1987; Smith \& Osherson, 1984; Smith, Osherson, Rips, Albert, \& Keane, in press) have been used to explore the notion that concepts are embedded in theorylike schematic structures (Murphy \& Medin, 1985). A full treatment of these issues may be found elsewhere (Cohen \& Murphy, 1984; Hampton, 1987b, 1988; Osherson \& Smith, 1981, 1982). The aim of the present paper is to extend the range of this discussion by presenting preliminary evidence concerning the disjunction of concepts.

The critical question in much of this research is the extent to which the operation of combining concepts into conjunctions and disjunctions corresponds to some form of set logic. Proponents of the extensional view argue that

This research was supported by a personal research award to the author from the British Academy, and by a Nuffield Foundation Social Science Fellowship. Grateful acknowledgment is due to the Psychology Department of Stanford University for hospitality and for providing the subjects for Experiment 1. Thanks are also due to Larry Barsalou, Herb Clark, John Gardiner, and Doug Medin for discussion of the work, and to Tony Heron and Antonia Gongora for research assistance. Requests for reprints should be sent to James A. Hampton, Memory and Cognition Research Unit, City University, Northampton Square, London EC1V 0HB, England.
Boolean set theory, which defines conjunction as the intersection of two sets, and disjunction as the union of two sets, can be extended to cover the case of fuzzy concepts whose set membership is not all-or-none, but is graded. In a well-known example of this approach-Zadeh's (1965) fuzzy logic-membership in a set is assigned a value between zero and one, and set combinations are achieved by applying a combination function to the constituent values to yield the value for the complex set. In the case of disjunctions, Zadeh proposed two possible functions: a maximum rule, whereby membership in the disjunction is the greater of the two constituent values, and an additive rule, whereby membership values are added (using the function $A+B-A \times B$ ) as if they were the probabilities of two independent events. These two functions have the advantage (for an extensional approach) that they preserve many of the Boolean constraints on set membership. An item cannot have a lower membership value in a disjunction than in any one constituent, and if membership values are restricted to zero or one, then both functions reduce to simple set union. The major qualitative difference between the functions is that the additive rule allows disjunctive membership to take values greater than either constituent membership value. According to extensional theories, then, membership in a disjunction is determined simply as a function of the two constituent membership values.

The alternative position proposes an intensional basis for conceptual combination. In the case of conjunctions, previous work (Hampton, 1987a, 1987b, 1988) showed that people may judge items to belong in conjunctions that they would not judge to belong in one of the constituent categories. For example, chess might be judged to be a GAME which is a SPORT, and yet not be judged to be a SPORT. In many cases, a form of compensation appeared to take place, allowing good membership in one category to offset poor membership in the other, so that the chance of belonging to the conjunction lay in between that for the two constituents. The occurrence of this overextension of conjunctions was explained by the idea that 
the attributes that compose the prototype representation of each constituent concept are themselves combined according to some set of intensional composition rules, in order to generate a composite prototype for the concept conjunction. Both membership and typicality judgments for the conjunction are then determined by the same unitary underlying dimension, namely similarity of an item to the composite prototype of the conjunction. In support of this model, Hampton (1987a, 1988) showed additionally that for a number of conjoined pairs of concepts, one of the concepts played a larger role in determining an item's typicality and likelihood of belonging in the conjunction than did the other. This "concept dominance" effect was related in a subsequent study (Hampton, 1987b) to the relative number of salient attributes that the two concepts in question possessed, and the degree to which those attributes were considered important to the definition of the conjunction. Hampton (1987b) also showed that the importance of an attribute for defining the conjunction was a function both of the two constituent importances and of the degree of coherence between each attribute of one constituent and those of the other constituent.

The present experiments aimed to extend the scope of research into conceptual combination to include concept disjunctions. Since there is an almost complete lack of detailed evidence on how fuzzy categories are disjoined, the topic is obviously worthy of interest. Even theoretical treatments have been scant. Osherson (1978) considered a naturalness constraint on forming a disjunction of two classes, namely that they should fall within the same ontological domain (Keil, 1979) within a predicability tree (Sommers, 1959). Smith and Medin (1981) discussed disjunctive concepts in the rather different sense of concepts that have a number of rather different prototypical exemplars (e.g., FURNITURE, which could be thought of as a disjunction of TABLES, BEDS, CUPBOARDS, and CHAIRS). The only attempt to consider logically formed disjunctions was Osherson and Smith's (1981) discussion of WEALTH, which they set up as a disjunction of CAPITAL ASSETS and LIQUIDITY. They used the example to disprove the validity of Zadeh's (1965) maximum rule (since increasing either element increases overall total wealth, and hence prototypicality as a "wealthy person"). Unfortunately, the example was poorly chosen, in that their analysis can be discounted simply on the grounds that WEALTH is a quantitative dimension and not a disjunctive concept. It therefore remains an open question whether Zadeh's rules may account adequately for concept disjunction. If it can be shown that they do, then the extensional model will be sufficient for at least one form of conceptual combination. On the other hand, if evidence is found that, like conjunctions, disjunctions produce class membership decisions that are sometimes inconsistent with either Boolean or fuzzy set logic, then the intensional model may have to be widened in its scope to encompass disjunctive as well as conjunctive composites. In particular, it may prove possible to show how the relative importance of attributes that form the intension of one concept are affected by placing the concept in the context of a disjunction.

A simple hypothesis of how context effects may arise is the proposal that attributes that the two concepts have in common will be increased in weight, whereas the weight of distinctive attributes may be reduced. Items may then possess a sufficiently strong similarity to one concept to belong in that concept category, but may be insufficiently similar to the modified concept representation to be included in the disjunctively defined class. This mechanism would produce underextension in the disjunction. The same principle might also lead to overextension, for example, where an item possesses all the attributes that are in common between two disjoined concepts, but is not sufficiently similar to either to belong in either constituent set. It was not the aim of the present experiments to develop such a model in any detail. The initial aim was to gather data on how disjunctive membership and typicality judgments are made, with the aim of determining the possible occurrence of either underextension or overextension in people's judgments.

As well as examining the consistency of judgments with respect to set union, the experiments also looked for parallels to some of the other phenomena observed for conjunctions, namely the predictability of item typicality in complex concepts as a function of constituent typicality, order effects within the complex concepts, and dominance effects between different members of concept pairs, whereby one member of a pair has a stronger influence on membership and typicality in the complex concept category.

\section{EXPERIMENT 1}

A disjunction is defined logically as the set of objects that are either in one category, or in another, or in both. In psychological terms, disjunction differs from conjunction in that there is no logical constraint that two concepts placed in disjunction should be semantically related. Although conjunctions of unrelated categories almost always result in an empty set, the same is not true of disjunctions. For example, consider the disjunction of things that are either UMBRELLAS or THEOREMS. Obviously, such combinations are absurd except in very unusual contexts (e.g., in the category "Things easily forgotten"; see Barsalou, 1983), and may have little interest psychologically, except to demonstrate that in most normal contexts there are strong constraints on what disjunctions appear natural (Osherson, 1978). For such unrelated disjunctions, and in the absence of an ad hoc context to make sense of the disjunction, it seems highly likely that Zadeh's (1965) maximum rule for disjunction would apply. An item is a good member of UMBRELLAS OR 
THEOREMS only to the extent that it is a good UMBRELLA or a good THEOREM, whichever is the greater.

For more natural disjunctions, however, such as HOBBIES OR GAMES and FRUITS OR VEGETABLES, where the items are drawn from the same superordinate class, and are either contrasting or overlapping categories, the question of how typicality and membership in a disjunction are determined is not intuitively obvious, simply because the degree of membership will not always be zero in at least one set, as it is in the example of UMBRELLAS OR THEOREMS. Given that in conjunctions there is evidence that the formation of composite representations leads to compensation between constituent memberships, might some similar process not also occur for some disjunctions? The possible interaction of attribute weights between two disjoined concepts is likely to be strongest among such related concepts. If compensation did occur, then two possible types of inconsistency may arise in the use of disjunctions. First, items may be judged to belong in one class, but not in the disjunction of that class with another (underextension). This effect might arise where an item is peripheral to the first class and very distant from the second. The context provided by the second concept may then be sufficient to change the relative weight of attributes in the first concept in such a way as to leave the item out of the disjunction. Second, items may be judged to be in neither class alone, yet to belong in their disjunction. Overextensions of this kind might be expected where the item is excluded from each constituent category, but is closely related to each. Having the common attributes of the two concepts, and given that such attributes mutually support each other's strength, the item may then become sufficiently similar to the disjunction to belong. (Overextensions, but not underextensions, could also be consistent with Zadeh's, 1965, interactive additive rule for disjunction.)

Earlier work on regression functions for predicting typicality in conjunctions (Hampton, 1987a, 1988) can be used to derive a prediction for disjunctions. It is well known that a disjunction can be expressed purely in terms of conjunction and negation:

$$
\text { A OR B }=\text { NOT [NOT(A) AND NOT(B)]. }
$$

Earlier research (Hampton, 1987a, 1988) suggested that many conjunctions can be predicted by the multiplication of membership values (with linear rescaling), and that negation as a first approximation is an operator changing the sign of a membership value. If these functions are used to produce an algebraic expression for NOT [NOT(A) AND NOT(B)], the expression can be shown to have the following form:

$$
\begin{aligned}
c(\mathrm{~A} \text { OR B })= & a_{0}+a_{1} \times c(\mathrm{~A})+a_{2} \times c(\mathrm{~B}) \\
& -a_{3} \times c(\mathrm{~A}) \times c(\mathrm{~B}),
\end{aligned}
$$

where $a_{0}$ to $a_{3}$ are positive constants. Thus, if conjunction involves a positive interaction term in the regression equation, it follows that disjunction should have a negative interaction term. It may be noted that the function reduces to Zadeh's (1965) additive function for set disjunction, given $a_{0}=0$, and $a_{1}$ to $a_{3}=1$.

\section{Method}

Subjects. A total of 40 undergraduate students at Stanford University, taking an introductory course in psychology, participated for course credit.

Design and Materials. The design was a repeated measures design, with order effects balanced across subject groups. Each subject rated items in each of two constituent categories (e.g., HOBBIES and GAMES) and 1 week later rated the same items in their disjunction (e.g., HOBBIES OR GAMES). Each of the three rating tasks used a different random order of the list of items. The eight disjunctions, presented in a different random order in each booklet, were HOBBIES OR GAMES, FRUITS OR VEGETABLES, TOOLS OR INSTRUMENTS, FURNITURE OR HOUSE FURNISHINGS, PETS OR FARMYARD ANIMALS, HERBS OR SPICES, KITCHEN UTENSILS OR HOUSEHOLD APPLIANCES, and SPORTS EQUIPMENT OR SPORTSWEAR. In each case, the disjunctions named related categories of items in the same domain, with varying degrees of overlap. The 24 items selected for each disjunction had varing degrees of membership and nonmembership in each category. There were two between-subjects order factors. Half of the subjects rated the constituent concepts of each disjunction in one order (e.g., HOBBIES then GAMES), and half in the reverse order. Within each of these groups, half of the subjects then received the disjunction phrased in one order (e.g., HOBBIES OR GAMES), and half in the reverse order (e.g., GAMES OR HOBBIES).

Procedure. The subjects were run in groups of between 5 and 10. They were given a booklet with instructions on the cover, on which they wrote their names so that responses could be matched up. The 24 items for each list were typed in a column beneath the category name, and the subjects worked down each list, giving a rating response to each item using a rating scale printed at the top of each page. As in earlier research (Hampton, 1982, 1987a, 1988), the rating scale and instructions emphasized that subjects should first decide whether an item belonged in the named category (or disjunction of categories). If it did belong, positive ratings from +1 to +3 were to be given to indicate increasing degrees of typicality. If it did not belong, negative ratings from -1 to -3 were to be given to indicate decreasing relatedness to the category. A response of zero could be given to borderline cases if necessary. Unknown items were to be crossed out, and such responses were excluded from the analysis. There was no time constraint. Each subject attended for two sessions, exactly 1 week apart. No subject failed to return for the second half of the experiment.

\section{Results}

The analysis of the results is described in two sections. In the first, the individual responses of each subject to each item for the three category judgments were analyzed for their consistency with Boolean set union. In the second analysis, mean ratings were entered into regression equations to test how well typicality within the disjunction could be predicted as a function of constituent typicality.

Consistency of classification. To test how consistently subjects judged disjunctive class membership, each subject's set of three responses to each item was classified into one of eight types of triple (defined as [Category A, Category B, Disjunction]), according to the pattern of 
positive or negative ratings. Consistent triples were $[+++],[+-+],[-++]$, and $[---]$. Inconsistent triples consisted of underextensions $([++-],[+--]$, and $[-+-])$ and overextensions $([--+])$. Table 1 shows the relative frequency of each of these triples, for each disjunction.

A considerable proportion of triples were inconsistent. Overall, $5 \%$ of items judged to belong in both categories were excluded from the disjunction, $17 \%$ of items belonging in only one category were excluded, and $23 \%$ of items in neither category were included in the disjunction. Obviously, to interpret these data, some allowance must be made for random variation in subjects' responding. Following an analysis technique developed for studying conjunctions (Hampton, 1988), a model was constructed to estimate how much inconsistency could be expected based on two simple hypotheses. The first was that subjects may be less generous when rating the same set of items in a second individual category, having previously judged their membership in a first. This effect was identified in previous experiments on overlapping categories (Hampton, 1988, Experiments 2 and 3), and was also seen in the present data. On average, subjects made 15.2 positive ratings (probability $p=.64$ ) to a category in the first position, and only $13.7(p=.58)$ in the second position. (Categories were evenly balanced across order conditions.) The difference was found in 14 of the 16 categories $[t(15)=3.8, p<.01]$. This effect was originally seen as a contrast effect. Hampton (1988) suggested that subjects may be less willing to put an item in the second category, if they have recently put it in the first; however, a closer look at the present data failed to support this notion. Conditional probabilities showed that the reduction on the second response was entirely restricted to items that had been rated negatively for the first category (the probability of a positive second rating was .63 given a positive first rating, but only .50 given a first rating that was negative). It would therefore be more accurate to consider the overall negative bias on the second rating as an effect of perseverance of the initial negative rating than as one of contrast. On the other hand, it is possible that this interaction of the order effect with the first response was caused by a net positive association between the two responses across subjects. The order effect worked to increase the incidence of apparent overextensions by

Table 1

Observed and Predicted Frequencies of Triples of Positive or Negative Rating Responses in Experiment 1, for the Two Constituent Concepts A and B, and Their Disjunction (D), Together with Percentage of Triples Inconsistent with Set Union (\%)

\begin{tabular}{lrrrrrrr}
\hline & \multicolumn{3}{c}{ Observed } & & \multicolumn{3}{c}{ Predicted } \\
\cline { 2 - 4 } \cline { 6 - 7 } & D+ & D- & \%I & & D+ & D- & \% I \\
\hline A+ B+ & 2867 & 146 & 5 & & 2882 & 23 & 1 \\
A+ B- & 2587 & 544 & 17 & & 3093 & 259 & 8 \\
A- B- & 303 & 1008 & 23 & & 330 & 871 & 27 \\
\hline
\end{tabular}

depressing the probability of a positive constituent rating for the second rated item.

The second hypothesis was that there may be a degree of inconsistency because of the probabilistic nature of the categorizations. For many items, the chance of receiving a positive rating lies somewhere between zero and one. If a subject remakes the category decision for each category at Stage 2, and then applies a set union rule to the result, he/she may not be consistent with the ratings given a week earlier at Stage 1 (see McCloskey \& Glucksberg, 1978). The model incorporated a parameter $u$, which was the hypothesized probability that the subject would produce the same individual category judgment at Stage 2, either through recalling the previous occasion, or because of consistent individual variation between subjects. The model assumed that if either decision was not recalled, then it would be made afresh, with the same probability of a positive response as was observed in the subject groups rating that category in first position. Thus, for example, the probability of a triple of +++ , given the rating order $A$ then $B$, could be predicted from Equation 3:

$$
\begin{aligned}
p[+++]= & p_{a 1} \cdot p_{b 2} \cdot\left\{u^{2} \cdot 1+2 u(1-u) \cdot 1\right. \\
& \left.+(1-u)^{2} \cdot\left(p_{a 1}+p_{b 1}-p_{a 1} \cdot p_{b 1}\right)\right\},
\end{aligned}
$$

where $p_{a 1}$ is the probability of being classed in category $A$ when rated first (and similarly, $p_{b 1}$ and $p_{b 2}$ are the probabilities of being in category $B$ when rated first and second, respectively), $u^{2}$ is the probability of recalling both original judgments, and $2 u(1-u)$ is the probability of recalling only one. In both situations, the probability of a positive disjunction response is 1 . When neither is recalled [probability of $(1-u)^{2}$ ], then the chance of obtaining a positive response is obtained from the union of the two unbiased estimates of the constituent probabilities, $p_{a 1}$ and $p_{b 1}$ (assuming independence).

Table 1 shows the expected level of inconsistency with $u$ set arbitrarily to .5 (which earlier studies showed to be a reasonable estimate; Hampton, 1988). The model was a poor estimator of the observed levels of inconsistency. In particular, there was much more underextension and much less overextension than would be predicted on the basis of the model. Overall, the disjunctions were underextended: items were judged to belong to one or both sets but not to their disjunction. The average expected frequency of positive disjunction ratings, based on Boolean set union, would be 19.2. The observed number was 18.0 . If $u$ is set sufficiently high, then it is just possible to account within the model for the $23 \%$ overextension observed overall, but only at the expense of greatly increasing the underestimation of the likelihood of underextensions. On the other hand, even with $u$ reduced to zero, the degree of underextension observed was considerably larger than could be accounted for by the model.

The stochastic model assumed independence between the probabilities of belonging to each category. Taking 
the response distributions overall, the data did not deviate too greatly from this assumption. As mentioned previously, there was a small positive association between the responses for most disjunctions. Unfortunately, it is not possible to disconfound a real association from a possible artifactual association that may have resulted from the repeated testing of the same items in the same experimental session.

As an alternative way of assessing overall underextension, which makes fewer assumptions, Table 2 shows the predictions made from Zadeh's (1965) two disjunctive rules (taking constituent probability values from first ratings only) compared with the observed levels of positive disjunctive responses. The table shows the probability of a positive response to the disjunction for each pair of concepts, and the degree of fit of the maximum and the additive rules. It can be seen that in seven of the category pairs for the additive rule and in six for the maximum rule, the observed probability was less than predicted. Even with maximal positive association between the two judgments, it should not be possible for membership in the disjunction to fall below the greater of the two constituent probabilities. Furthermore, the root mean squared deviation averaged .14 for the additive rule and .11 for the maximum rule, suggesting a relatively poor fit to individual item probabilities.

Individual items giving rise to underextension and overextension are shown in Appendix A, together with the observed and expected frequencies of inconsistent triples and the three mean membership ratings. Most cases of double underextensions $[++-]$ had both membership values close to the borderline. For example, mean ratings for RACE HORSE were 0.42 for PETS and 0.05 for FARMYARD ANIMALS (on a scale from -3 to +3 ). For the cases of single underextension, many items had a borderline rated membership in one category (column A), and a more strongly negative rating in the other category (column B). For the 32 underextensions in Appendix A, mean $A$ was +0.44 , and mean $B-1.24$. A reasonable explanation for underextension, therefore, is that (just as in the case of conjunctions) subjects' ratings may follow some form of compensatory average rule, where membership in the disjunction lies between the two constituent memberships. In fact, 26 of the 32 underextended items had mean ratings for the disjunction that lay between the $A$ and $B$ values, and overall some $50 \%$ of the items had a mean disjunctive rating below that for one or the other constituent.

Also shown in Appendix A are those items for which overextension occurred $([--+])$. As may be expected, they tended to be items whose memberships in each set were near the borderline. Average membership in either category was -0.81 across these items. Average disjunctive membership was +0.13 , and in 14 of the 16 items, the mean disjunction rating was higher than for either of the two constituents. As suggested by the data in Table 2, most of the cases of overextension came in the two disjunctions TOOLS OR INSTRUMENTS and FRUTTS OR VEGETABLES.

Regression analysis. Mean ratings for A, B, and their disjunction were entered into regression equations that predicted the disjunctive rating from the two constituents and their product. For conjunctions of the form "A that are also B," Hampton (1988) found that the second noun B-the qualifier-was accorded greater weight in the regression equations. In the present experiment with disjunctions, there was no such effect (as may be expected, given that the syntactic construction is quite different and much more symmetrical for the disjunctions). Nine of the 16 categories had higher beta weights when placed first in the disjunction, 6 were higher when placed second, and 1 showed no difference. On simple regression weights, half the categories had higher weights when placed first, and half when placed second. The two order conditions were therefore combined to provide a mean rated membership in the disjunction based on all $\mathbf{4 0}$ subjects. Regression equations were calculated to predict mean rated disjunctive membership from the mean ratings for the constituent categories, based only on the subject groups rating each category first. The resulting regression statistics are shown in Table 3.

$R$ varied from 0.945 to 0.988 . Mean adjusted $R^{2}$, the proportion of variance explained, was .93 , and mean standard error of prediction was 0.325 . The fit of the equations was excellent. Both constituents entered the equation with significant positive weights in all equations. In

Table 2

Observed Probability of Positive Ratings for Each Disjunction, Together with Predicted Values

Based on an Additive and a Maximum Rule for Fuzzy Disjunction, Mean Deviation (DEV) from Observed Values, and Root Mean Squared Deviation (RMSD), for Experiment 1

\begin{tabular}{|c|c|c|c|c|c|c|c|c|}
\hline \multicolumn{2}{|c|}{ Category } & \multirow[b]{2}{*}{ Observed $p$} & \multicolumn{3}{|c|}{ Additive } & \multicolumn{3}{|c|}{ Maximum } \\
\hline A & B & & $p$ & DEV & RMSD & $p$ & DEV & RMSD \\
\hline FURNITURE & HOUSE FURNISHINGS & .82 & .93 & -.11 & .15 & .89 & -.07 & .11 \\
\hline GAMES & HOBBIES & .85 & .93 & -.08 & .11 & .90 & -.05 & .09 \\
\hline PETS & FARMYARD ANIMALS & .72 & .85 & -.13 & .19 & .80 & -.08 & .14 \\
\hline HERBS & SPICES & .74 & .85 & -.11 & .16 & .79 & -.05 & .09 \\
\hline TOOLS & INSTRUMENTS & .79 & .87 & -.08 & .12 & .78 & +.01 & .08 \\
\hline SPORTSWEAR & SPORTS EQUIPMENT & .76 & .85 & -.09 & .13 & .80 & -.04 & .09 \\
\hline HOUSEHOLD APPLIANCES & KITCHEN UTENSILS & .76 & .84 & -.08 & .14 & .80 & -.04 & .10 \\
\hline FRUITS & VEGETABLES & .74 & .70 & +.04 & .10 & .68 & +.06 & .13 \\
\hline MEAN FIT & & & & -.08 & .14 & & -.03 & .11 \\
\hline
\end{tabular}


Table 3

Regression Statistics for Predicting Mean Rated Membership in a Disjunction from Mean Rated Membership in Each Constituent, and Their Interaction, in Experiment 1

\begin{tabular}{|c|c|c|c|c|c|c|c|c|}
\hline \multicolumn{2}{|c|}{ Category } & \multicolumn{3}{|c|}{ Regression Weights } & \multicolumn{3}{|c|}{ Beta Weights } & \multirow[b]{2}{*}{$\boldsymbol{R}$} \\
\hline A & $\mathbf{B}$ & $\mathbf{A}$ & B & $\mathbf{A} \times \mathbf{B}$ & A & B & $\mathbf{A} \times \mathbf{B}$ & \\
\hline HOUSE FURNISHINGS & FURNITURE & .663 & .351 & .0 & .643 & .430 & .0 & .951 \\
\hline HOBBIES & GAMES & .734 & .503 & -.143 & .672 & .776 & -.436 & .958 \\
\hline SPICES & HERBS & .671 & .370 & .0 & .634 & .384 & .0 & .980 \\
\hline INSTRUMENTS & TOOLS & .587 & .490 & .0 & .510 & .507 & .0 & .968 \\
\hline FARMYARD ANIMALS & PETS & .773 & .707 & -.212 & .869 & .642 & -.321 & .963 \\
\hline SPORTS EQUIPMENT & SPORTSWEAR & .816 & .219 & .0 & .830 & .271 & .0 & .981 \\
\hline HOUSEHOLD APPLIANCES & KITCHEN UTENSILS & .649 & .508 & -.157 & .659 & .718 & -.291 & .945 \\
\hline FRUITS & VEGETABLES & .585 & .539 & -.104 & .797 & .627 & -.202 & .988 \\
\hline
\end{tabular}

Note-In each pair, the concept with the higher regression weight is listed first. Where a variable did not enter significantly, a weight of .0 is shown.

four of the eight disjunctions, there was also a significant negatively weighted interaction term. The negative weight agrees with the prediction made from the analysis of conjunctions and suggests that (with suitable rescaling) Zadeh's (1965) interactive disjunction rule may possibly be used to predict disjunctive membership ratings. (It is unclear why only half of the disjunctions should show a significant interaction term. It may, of course, reflect the relative abundance in the lists of particular types of item. Experiment 2 replicated the study to see how consistently this pattern emerges, and whether it may reflect random factors in the selection of items.)

One of the interesting results established by earlier research on conjunctions was the concept dominance effect, whereby the two concepts making up a conjunction carried different weights in predicting typicality in the conjunctive category. The weights in Table 3 suggest a similar phenomenon for some disjunctions. Some pairs were evenly matched, but in each of the following pairs, the first-named concept had a regression weight more than .2 higher than the second: HOUSEHOLD FURNISHINGS OR FURNITURE, SPICES OR HERBS, SPORTS EQUIPMENT OR SPORTSWEAR, and HOBBIES OR GAMES. The effect was not due to restricted range, since the average variance for dominant and nondominant concepts overall was similar. An adequate account of the effect could, however, be given in terms of relative inclusiveness. Overall, there were only $3 \%$ of response triples in which an item was judged to be FURNITURE but not to be a HOUSE FURNISHING. Similarly, only $6 \%$ were GAMES but not HOBBIES, 7\% were HERBS but not SPICES, and $8 \%$ were SPORTSWEAR but not SPORTS EQUIPMENT. In each case, the dominant category was a near superset of the nondominant one. The dominance observed in these disjunctions, therefore, may be of less theoretical interest than dominance in conjunctions, since it probably reflects the relative number of items in the list that depend solely on membership in one (or the other) category in order to belong in the disjunction. If category $\mathbf{A}$ is nearly contained within category $\mathbf{B}$, then membership in B is sufficient for membership in the disjunction, and membership in A may become almost irrelevant.
A final analysis took each of the $7 \times 7$ possible combinations of ratings for the two constituent categories and calculated the mean disjunction rating given to each. The results are shown in Table 4 , where it can be seen that mean rated membership in the disjunction declined smoothly as rated constituent membership declined along each axis of the table. The data in Table 4 were used to produce by extrapolation the graphs shown in Figure 1, which shows contours of equal disjunctive membership, with the vertical axis representing membership in the first noun class of the disjunction, and the horizontal axis representing membership in the second. The contours were derived using a linear extrapolation between neighboring cells in the rows and columns of Table 4 . For example, for a second response of -3 (first column in Table 4), a first response of -3 had a mean disjunctive rating of -2.148 , whereas a first response of -2 had a mean disjunctive rating of -1.856 . A point for the contour labeled -2 for the disjunction could therefore be derived, with coordinates of a second rating of -3 , and a first rating lying at a point between -3 and -2 , such that the disjunctive rating would have had a value of exactly -2.0 (assuming a linear function).

The best example of the disjunction lies in the top right corner of the graph, where items are highly typical of both sets. Similar contour graphs for conjunctions (Hampton, 1987a, 1988) typically showed concave contours radiating out from this corner. For disjunctions, the curvature of the contour lines was convex. This curvature reflects

Table 4

Mean Rated Membership in a Disjunction, as a Function of the Individual Combination of Ratings Given for Each Constituent Concept, to Each Item by Each Subject, for Experiment 1

\begin{tabular}{cccccccc}
\hline \multirow{2}{*}{$\begin{array}{c}\text { First } \\
\text { Response }\end{array}$} & \multicolumn{7}{c}{ Second Response } \\
\cline { 2 - 8 } & -3 & -2 & \multicolumn{1}{c}{-1} & 0 & +1 & +2 & +3 \\
\hline-3 & -2.148 & -1.484 & -1.009 & - & -0.217 & 1.429 & 2.461 \\
-2 & -1.856 & -0.921 & -0.737 & 0.455 & 0.195 & 1.024 & 2.387 \\
-1 & -1.111 & -0.487 & -0.018 & 0.0 & 0.371 & 1.321 & 2.417 \\
0 & - & -0.200 & 0.500 & 0.800 & 1.083 & - & 2.500 \\
+1 & -0.147 & 0.481 & 0.916 & - & 1.206 & 1.566 & 2.575 \\
+2 & 1.509 & 1.257 & 1.643 & - & 1.758 & 1.989 & 2.668 \\
+3 & 2.242 & 2.267 & 2.429 & - & 2.444 & 2.529 & 2.787 \\
\hline
\end{tabular}

Note-A dash indicates missing data points. 


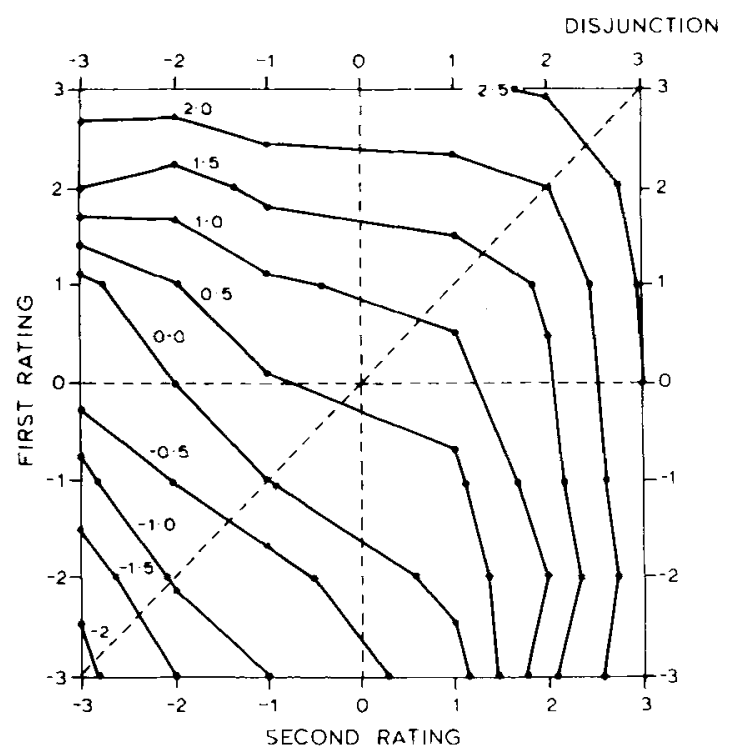

Figure 1. Lines of equal membership in the disjunction drawn for different membership ratings for the first (vertical axis) and the second (horizontal axis) categories to be rated, summed over all responses in Experiment 1.

the fact established in the regression analysis that, whereas conjunctions had a positive interaction term, disjunctions had a negative interaction term. In simple terms, this difference occurs because, whereas items that are good members of one concept but not of the other are worse members of a conjunction than a straight weighted average of constituent typicalities would predict, they are better members of a disjunction.

The pattern of overextension and underextension described earlier can be seen in the placement of the category borderline in Figure 1. Whereas a strict set union rule would fix a category boundary to include in the disjunction all areas of the space except for the lower left quadrant, the actual data suggest that the category boundary could be defined as a straight line with a slope of -1 , drawn through the lower left of the graph. As a result, there were areas of both overextension (between the borderline and the origin in the center) and underextension (where the borderline crosses into the top left and bottom right quadrants). Although the typicality functions for members of the disjunction were quite strongly curved, the straight borderline suggests that membership in the disjunction was in fact based on a fairly simple weighted average of the two constituent membership values.

\section{EXPERIMENT 2}

The results of Experiment 1 supported the notion that people's judgments of disjunctive category membership follow neither a Boolean set union rule nor one derived from fuzzy logic (Zadeh, 1965). Subjects' judgments showed both underextension and overextension of disjunctions. Half of the disjunctions studied had fairly strong negative interaction terms in the regression equations, predicting typicality in the disjunction from constituent typicality. There was also evidence of a dominance effect in some of the disjunctions, which was best explained in terms of relative inclusiveness of the categories. Before we move to a fuller discussion of the theoretical implications of these results, a second experiment will be described that aimed to support these results by using a similar set of items within the same eight conjunctions. Experiment 2 was designed as a replication using a new subject population and a between-subjects design. The aim of the replication was to provide a test of the generality of the particular results obtained. One problem in the interpretation of Experiment 1 was that, when items were rated for membership of each of a pair of categories in the same session, the mean number of positive ratings was less when the category was rated second than when it was rated first. The possibility that repeated testing of the same items may be having other unintended effects on category membership judgments can be eliminated through the use of separate groups of subjects for the different category ratings. The use of a between-subjects design also allowed the use of probability theory to support the two fuzzy disjunction rules considered previously. The additive rule corresponds to the case in which the two constituent category decisions are stochastically independent, whereas the maximum rule provides a lower bound on disjunctive probability where the two decisions are positively associated.

\section{Method}

Subjects. A total of $\mathbf{4 0}$ undergraduate students at The City University, London, acted as paid volunteer subjects; there were 10 subjects per group.

Design and Materials. The experiment used a between-subjects design. There were four groups of subjects. Group 1 rated a list of items for one constituent of each disjunction, and Group 2 rated the list for the other constituent. Groups 3 and 4 then rated the lists for the disjunction itself, with the order of concepts within the disjunctive phrase being switched between the groups. The same eight disjunctions were employed as in Experiment 1, and 24 items were again selected for each disjunction, including many but not all of those used in Experiment 1. In all, 24 (12\%) of the Experiment 1 items were replaced. The replacements were affected partly to change the distribution of items across categories, and partly to adapt the materials for British students.

Procedure. The subjects were tested individually, and worked through a booklet with the same standard instruction sheet and rating scale as in Experiment 1, and with eight lists of 24 items, each typed in a column under a concept heading, and printed two lists to a page. Each subject took part in only one session.

\section{Results}

The results were analyzed in two ways. First, regression analyses were used to predict mean rated typicality of items in a disjunction from their constituent typicalities. Second, individual probabilities of positive classification $p[+]$ were used to examine the frequency of overextension or underextension of the disjunctions, independently of judged typicality.

Regression of mean ratings. Regression equations were used to predict mean membership ratings in the dis- 
junctions from mean constituent membership values. Regressions for the two forms of the disjunctions were first calculated individually. As in Experiment 1, there was no systematic effect of order on the regression weights, so the two disjunction ratings were averaged, and regression equations were used to predict a single combined mean rating for each disjunction. The regression statistics are shown in Table 5 .

$R$ ranged from .859 to .971 . Mean adjusted $R^{2}$ was .86 , and the mean standard error of prediction was .512. Thus the mean ratings were again highly predictable, although rather less so than in Experiment 1 . Interaction terms entered significantly in five of the eight equations, including all four of those that had significant interaction terms in Experiment 1. There was thus a close correspondence between the experiments in the strength of the interaction terms. The correspondence in dominance was not quite so close. Of the four disjunctions in Experiment 1 showing a dominance effect, HOUSE FURNISHINGS still dominated FURNITURE, and SPORTS EQUIPMENT dominated SPORTSWEAR, and in both cases the latter category was largely included in the former. HERBS and SPICES were more evenly weighted, but also showed a more even distribution. There were, however, two disjunctions going against the general account of dominance in terms of relative inclusiveness of the categories. HOBBIES and GAMES showed the same inclusion relation as before, with most GAMES being HOBBIES, but not vice versa, yet their regression weights were similar. On the other hand, PETS and FARMYARD ANIMALS were evenly distributed, and yet showed quite a strong dominance effect (of PETS over FARMYARD ANIMALS). It may be concluded that, although item distribution can clearly affect the relative dominance of the categories in the regression equations, there is some evidence that there may be other factors at work. A clear answer can be obtained only by preselecting a set of items to be evenly distributed between the two categories, and collecting further data.

Classification probability. Experiment 1 showed that individual subjects may make inconsistent sets of responses to items in disjunctive categories. To test for similar effects in the present experiment, the individual probabilities of positive classification of an item in each category were compared. For each item and each subject group, four probabilities $p[+]$ were calculated by dividing the number of positive ratings by the total number of nonzero responses. The advantage of taking this measure from a between-subjects design is that it provides a straightforward measure of the membership of the categories, removing any differences in typicality of members or relatedness of nonmembers. The purpose of the analysis was also to see whether either of Zadeh's (1965) fuzzy logic rules for mapping membership in two constituent sets onto membership in their disjunction would apply to the present data. Experiment 1 showed a general tendency for subjects to underextend the disjunctions, which would be consistent with neither of Zadeh's rules. The two rules for disjunction can be interpreted as rules for combining probabilities in the current analysis. If it is assumed that subjects judging a disjunctive concept make two statistically independent decisions about an item's membership in each constituent category, and make a final positive decision if either of those two decisions is positive, then $p[+]$ for the disjunction should follow the additive rule, since for two independent events $A$ and B,

$$
p(\mathrm{~A} \text { or } \mathrm{B})=p(\mathrm{~A})+p(\mathrm{~B})-p(\mathrm{~A}) \times p(\mathrm{~B}) .
$$

Of course, the decisions may not be stochastically independent. In the case in which the two decisions are positively associated, then the maximum rule (which proposes that membership in a disjunction is equal to the greater of the two constituent memberships) can be used to place a lower bound on the probability of being in the disjunction. It should not be possible for the probability of being in a disjunction to fall below the probability of being in one of the constituents.

The two models were fit to the data, comparing the outcome of the two functions with the observed $p[+]$ in the disjunctions. There was little difference between the two orders of disjunctions, so the data were combined. Table 6 shows the fit of the two models. Overall, both models overestimated the probability of classification in the disjunctions. Hence, the maximum model provided a better fit than the additive model (since it always pro-

Table 5

Regression Statistics for Predicting Mean Rated Membership in a Disjunction of Two Concepts from Mean Rated Memberships in Each Constituent, and Their Interaction, In Experiment 2

\begin{tabular}{|c|c|c|c|c|c|c|c|c|}
\hline \multirow[b]{2}{*}{$\mathbf{A}$} & \multirow[b]{2}{*}{ B } & \multicolumn{3}{|c|}{ Regression Weights } & \multicolumn{3}{|c|}{ Beta Weights } & \multirow[b]{2}{*}{$\boldsymbol{R}$} \\
\hline & & $\mathbf{A}$ & B & $\mathrm{A} \times \mathrm{B}$ & A & $\mathbf{B}$ & $\mathbf{A} \times \mathbf{B}$ & \\
\hline HOUSE FURNISHINGS & FURNITURE & .786 & .0 & .0 & .897 & .0 & .0 & .897 \\
\hline HOBBIES & GAMES & .547 & .426 & -.121 & .565 & .608 & -.394 & .938 \\
\hline HERBS & SPICES & .517 & .500 & .0 & .563 & .496 & .0 & .970 \\
\hline INSTRUMENTS & TOOLS & .544 & .461 & -.156 & .527 & .518 & -.220 & .924 \\
\hline PETS & FARMYARD ANIMALS & .687 & .429 & -.200 & .678 & .460 & -.321 & .971 \\
\hline SPORTS EQUIPMENT & SPORTSWEAR & .923 & .0 & .0 & .970 & .0 & .0 & .970 \\
\hline HOUSEHOLD APPLIANCES & KITCHEN UTENSILS & .666 & .615 & -.202 & .829 & 1.033 & -.622 & .945 \\
\hline VEGETABLES & FRUITS & .585 & .513 & -.129 & .530 & .655 & -.242 & .859 \\
\hline
\end{tabular}

Note-In each pair, the concept with the higher regression weight is listed first. Where a variable did not enter significantly, a weight of .0 is shown. 
Table 6

Observed Probability of Positive Ratings for Each Disjunction, Together with Predicted Values Based on an Additive and a Maximum Rule for Fuzzy Disjunction, Mean Deviation (DEV) from Observed Values, and Root Mean Squared Deviation (RMSD)

\begin{tabular}{|c|c|c|c|c|c|c|c|c|}
\hline \multirow[b]{2}{*}{ A } & \multirow[b]{2}{*}{ B } & \multirow[b]{2}{*}{ Observed $p$} & \multicolumn{3}{|c|}{ Additive } & \multicolumn{3}{|c|}{ Maximum } \\
\hline & & & $p$ & $D E V$ & RMSD & $p$ & DEV & RMSD \\
\hline FURNITURE & HOUSE FURNISHINGS & .69 & .85 & -.16 & .22 & .79 & -.09 & .17 \\
\hline GAMES & HOBBIES & .84 & .92 & -.08 & .14 & .92 & -.08 & .13 \\
\hline PETS & FARMYARD ANIMALS & .57 & .68 & -.11 & .17 & .64 & -.07 & .15 \\
\hline HERBS & SPICES & .61 & .63 & -.02 & .14 & .58 & +.03 & .15 \\
\hline TOOLS & INSTRUMENTS & .69 & .80 & -.11 & .17 & .73 & -.04 & .13 \\
\hline SPORTSWEAR & SPORTS EQUIPMENT & .72 & .82 & -.10 & .17 & .79 & -.07 & .14 \\
\hline HOUSEHOLD APPLIANCES & KITCHEN UTENSILS & .84 & .89 & -.05 & .10 & .85 & -.01 & .11 \\
\hline FRUITS & VEGETABLES & .65 & .56 & +.09 & .17 & .52 & +.13 & .21 \\
\hline MEAN FIT & & & & -.07 & .16 & & -.03 & .15 \\
\hline
\end{tabular}

vides lower predictions). Average root mean squared deviations across items were .16 for the union rule and .149 for the maximum rule, both of which show a relatively poor fit to the individual probabilities. The pattern was not uniform across the eight disjunctions. Six of the disjunctions were overestimated by both rules. However, HERBS OR SPICES had a $p[+]$ intermediate between the two rules, and the $p[+]$ for FRUIT OR VEGETABLES was actually considerably underestimated by both rules.

Appendix B shows how individual items fared; it shows those cases with either a marked overestimation or a marked underestimation of probability of belonging in the disjunction. Also shown are mean rating values. As in Experiment 1 (see Appendix A), some items showed underextension of the disjunction, while others showed overextension (particularly in the FRUIT OR VEGETABLES category).

In conclusion, the tendency toward underextension of disjunctions found in Experiment 1 was replicated. For six of the eight disjunctions, the $p[+]$ for the disjunction was lower than the greater of the two constituent $p[+]$ values, thus indicating that subjects were not applying a set union rule to constituent set membership decisions. The two exceptions to the underextension were the disjunctions HERBS OR SPICES and FRUITS OR VEGETABLES. The latter, in particular, showed considerable overextension with respect to the additive function. An explanation may lie in the strong negative association between membership in the two categories. Subjects treat the two sets as mutually exclusive, and mutually exhaustive. The assumption of stochastic independence in the additive model is therefore obviously inappropriate for this disjunction. The predicted $p[+]$ can be revised upward to take account of the strong negative dependency between the constituent probabilities. An upper limit on disjunctive $p[+]$, in the case of strong negative dependency, is the sum of the two constituent $p[+]$ values. This value would correspond to the case in which nobody would consider that an item could belong in both constituents. However, of the 21 listed overextended items in Appendix B, 14 were actually overextended beyond this upper limit. Some further explanation of overextension, therefore, still seems to be required.

\section{GENERAL DISCUSSION}

The results described here provide evidence that when people decide about the category membership of a disjunctively defined set, they tend to allow compensation between the two degrees of belonging to the two constituent sets. The same result was previously observed for conjunctions (Hampton, 1987a), but conjunctions were generally overextended, whereas disjunctions tended to be underextended overall. People were more willing to allow an item in a category considered singly than when the category was disjoined with another class in which the item clearly did not belong. In this case, compensation acted to remove those items from the disjunction that were borderline candidates for one constituent, but clearly not in the other. There was also evidence in the experiments for some overextension of disjunctions. The clearest case of this overextension occurred for the disjunction FRUTTS OR VEGETABLES. For example, almonds and mushrooms were not good members of either set singly, but were quite frequently placed in the disjunction.

What mechanisms or explanatory principles may underlie these effects? Let us consider first the underextension, which was the more widespread result. In both a within-subject comparison of response triples (Experiment 1) and a stochastic model of categorization probabilities (Experiment 2), simple effects of random variation in responding were ruled out. The underextension in Experiment 1 was shown to be far greater than could be expected simply from subjects changing their opinions about a categorization from one week to the next. In Experiment 2, which used independent groups of subjects to estimate the probabilities, it was shown that the probability of an item's being placed in the disjunction was actually lower than the probability of its being placed in one constituent alone. The cause of the underextension must presumably lie in the way that people combine the concepts in this task. Two possible explanations are considered.

The first is that when people make judgments about any category, there is some form of anchoring effect, such that if the category is made larger (through disjunction) or smaller (through conjunction), then subjects are con- 
servative in the extent to which they allow the category size to change. That is, they will tighten up the criterion for membership when a category is in a disjunction and relax it for a conjunction, in order to reduce the overall change in the class size. (Note, however, that the assumption here is of a category with a variable criterion for membership.) A similar account would point to the tendency of subjects to try to use the full range of a rating scale (Parducci, 1965; see also Jones, 1982). In a direct test of this account, Hampton (1988, Experiment 3) compared two groups who rated the same item lists for constituent membership, but rated different sets of items for the conjunction. One group (the standard group) rated the same list of items once more, whereas the second group (the augmented group) rated a new list, containing a subset of the original items, placed in a new list context. Specifically, negative items were dropped from the original list, to be replaced by several highly typical members of the conjunction. The effect, therefore, was to allow subjects to respond consistently to the conjunction, while still distributing their responses roughly equally between positive and negative sides of the rating scale. The results showed very little effect of this manipulation. In particular, there was no significant decrease in the frequency of overextension triples to the items in common between the two groups for the augmented condition group.

A second, more theoretically interesting account can be given in terms of a semantic context effect, which may operate as an interaction between the two concepts being combined. For example, HOUSEHOLD APPLIANCE as a single category may conjure up thoughts of a wide range of machinery used in the home. HOUSEHOLD APPLIANCE OR KITCHEN UTENSIL may change the interpretation of the former category to focus it more on the types of appliance commonly found in the kitchen. As a result, ELECTRIC TOOTHBRUSHES may be included in the category HOUSEHOLD APPLIANCE but excluded from the disjunction. Such context effects could be imagined to work, either by a mutual increase in the weighting of attributes that fit both categories (using a prototype theory representation of the two concepts; Hampton, 1987b; Rosch, 1978) or as an effect on the set of typical exemplars used to represent the category (if an exemplar-based representation is preferred; Medin \& Schaffer, 1978). Underextension could perhaps be due to subjects' attempting to find a common prototype for both categories (in this case, something like a food processor would fit best). The normal range of application of each concept will therefore be changed, and items normally included in a category may be left out of the disjunction.

If we then consider overextension in disjunctions, the second of these two accounts becomes more plausible than the first. If underextension were solely the result of a general tendency to operate a tighter criterion for concepts placed in disjunctions, then one would not expect to find overextension. It is, of course, logically quite pos- sible for the probability of being classified in a disjunction to exceed individual constituent probabilities. Depending on the degree of statistical dependence between the two constituent decisions, the disjunctive probability could vary between the maximum rule (in which one set is entirely contained within the other) and a sum rule (in which the two sets are entirely nonoverlapping). In Experiment 2, however, it was found that a fair proportion of items were overextended even beyond the sum of the two constituent values. As one subject put it, "I wouldn't like to commit myself to saying it was in either one alone, but it is certainly in one or the other." This quote would suggest that one cause of overextension in disjunctions is that when faced with a domain divided into two (almost) nonoverlapping categories (e.g., fruits and vegetables), a subject may exercise natural caution in judging whether a borderline case is in one or the other. No such doubt is experienced, however, in judging if the item falls in the domain as a whole. Although this may be a consistent account, it remains unmotivated. Why should caution prevail here? Why does such caution not rule out the cases that were found to be underextensions of disjunctions?

As with the previous case of underextensions, a semantic analysis may help to explain how overextension operates. Faced with a disjunction of two sets that are perceived (perhaps erroneously) as together defining a larger domain, subjects may choose to treat the disjunction as if it were the superordinate concept for the domain. Thus, given FRUITS OR VEGETABLES, subjects may decide that this disjunction defines FRESH PRODUCE (or GREEN GROCERIES in Britain) and may operate on that basis, including such items as MUSHROOM or ALMOND, which actually fall outside the two individual categories. Interestingly, the same hypothesized mechanism of mutual reinforcement of the weights of overlapping attributes could account both for the underextension previously discussed and for the overextension described here. The critical difference lies in the relation between the two categories being disjoined. For underextension, the categories are overlapping; for overextension, they are mutually exclusive members of the same superordinate set.

In summary, a semantic interaction effect in disjunctions has been proposed. When two categories are placed in disjunction, there is a tendency for a mutual interaction of attributes, with greater weight being attached to those attributes of each category that are compatible with the other (for a similar mechanism in conjunctions, see Hampton, 1987b). The effect of the interaction in which the two categories overlap to a considerable degree is to sharpen up the definition of each category by giving it some of the attributes of the other. Large, vaguely delineated categories can become more tightly focused when disjoined with others, thus causing items unrelated to the new context to be excluded. Conversely, where the 
overlap between two categories is slight, but they exist as contrasting sets within a superordinate, then the same semantic interaction of attribute weights may lead to distinguishing attributes being rendered less important, so that the remaining common attributes (which will be those of the superordinate) delineate a wider category than the Boolean disjunction of the two original sets.

\section{REFERENCES}

Barsalou, L. W. (1983). Ad hoc categories. Memory \& Cognition, 11, 211-227.

Cohen, B., Murphy, G. L. (1984). Models of concepts. Cognitive Science, 8, 27-58.

Hampton, J. A. (1982). A demonstration of intransitivity in natural concepts. Cognition, 12, 151-164.

Hampton, J. A. (1983). A composite prototype model of conceptual conjunction. Unpublished manuscript, The City University, London.

Hampton, J. A. (1987a). Conceptual combination: Conjunction and negation of natural concepts. Unpublished manuscript, The City University, London.

HAMPTON, J. A. (1987b). Inheritance of attributes in natural concept conjunctions. Memory \& Cognition, 15, 55-71.

HAMPTON, J. A. (1988). Overextension of conjunctive concepts: Evidence for a unitary model of concept typicality and class inclusion. Joumal of Experimental Psychology: Learning, Memory \& Cognition, 14, 12-32.

JONES, G. V. (1982). Stacks not fuzzy sets: An ordinal basis for prototype theory of concepts. Cognition, 12, 281-290.

KeIL, F. C. (1979). Semantic and conceptual development. Cambridge, MA: Harvard University Press.
McCloskey, M., \& GluCKsberg, S. (1978). Natural categories: Welldefined or fuzzy sets? Memory \& Cognition, 6, 462-472.

Medin, D. L., \& Schaffer, M. M. (1978). Context theory of classification learning. Psychological Review, 85, 207-238.

MurPHy, G. L. (1987). Comprehending complex concepts. Unpublished manuscript, Brown University, Providence, RI.

MurPhy, G. L., \& MEdin, D. L. (1985). The role of theories in conceptual coherence. Psychological Review, 92, 289-316.

Osherson, D. N. (1978). Three conditions on conceptual naturalness. Cognition, 6, 263-289.

Osherson, D. N., \& SiTh, E. E. (1981). On the adequacy of prototype theory as a theory of concepts. Cognition, 11, 35-58.

Osherson, D. N., \& SMITH, E. E. (1982). Gradedness and conceptual conjunction. Cognition, 12, 299-318.

ParduCCI, A. (1965). Category judgments: A range-frequency model. Psychological Review, 72, 407-418.

Rosch, E. (1978). Principles of categorization. In E. Rosch \& B. Lloyd (Eds.), Cognition and categorization (pp. 27-48). Hillsdale, NJ: Erlbaum.

Rosch, E., Mervis, C. B. (1975). Family resemblances: Studies in the internal structure of categories. Cognitive Psychology, 7, 573-605.

Smith, E. E., \& Medin, D. L. (1981). Categories and concepts (pp. 27. 48). Cambridge, MA: Harvard University Press.

SMith, E. E., \& Osherson, D. N. (1984). Conceptual combination with prototype concepts. Cognitive Science, 8, 337-361.

Smith, E. E., Osherson, D. N., Rips, L. J., \& KeAne, M. (in press). Combining prototypes: A selective modification model. Cognitive Science.

Sommers, F. (1959). The ordinary language tree. Mind, 68, 160-185.

Thagard, P. (1983, June). Conceptual combination: A frame-based theory. Paper presented at the Society for Philosophy and Psychol ogy, Wellesley, MA.

ZADEH, L. (1965). Fuzzy sets. Information \& Control, 8, 338-353.

ZADEH, L. (1982). A note on prototype theory and fuzzy sets. Cognition, 12, 291-297.

\section{APPENDIX A}

Items in Experiment 1 with More than 10\% Disjunctive Responses of Particular Inconsistent Types, Showing Frequency of Inconsistent Triple $(N)$, out of 20, and Mean Typicality in Constituents (A, B) and in the Disjunction (Disj)

\begin{tabular}{|c|c|c|c|c|c|c|}
\hline Category A & Category B & Item & $N$ & A & B & $\overline{\text { Disj }}$ \\
\hline \multicolumn{7}{|c|}{ Double Underextension $[++-]$} \\
\hline $\begin{array}{l}\text { HOUSE } \\
\text { FURNISHINGS }\end{array}$ & FURNITURE & $\begin{array}{l}\text { Counter } \\
\text { Waste Basket }\end{array}$ & $\begin{array}{l}5 \\
5\end{array}$ & $\begin{array}{l}1.32 \\
1.52\end{array}$ & $\begin{array}{r}0.40 \\
-0.30\end{array}$ & $\begin{array}{l}1.02 \\
0.70\end{array}$ \\
\hline HERBS & SPICES & $\begin{array}{l}\text { Horseradish } \\
\text { Parsley } \\
\text { Vanilla }\end{array}$ & $\begin{array}{l}5 \\
5 \\
5\end{array}$ & $\begin{array}{r}0.40 \\
2.05 \\
-0.92\end{array}$ & $\begin{array}{l}1.00 \\
0.42 \\
0.42\end{array}$ & $\begin{array}{r}0.87 \\
1.47 \\
-0.15\end{array}$ \\
\hline PETS & $\begin{array}{l}\text { FARMYARD } \\
\text { ANIMALS }\end{array}$ & Race Horse & 7 & 0.42 & 0.05 & 0.42 \\
\hline $\begin{array}{l}\text { SPORTS } \\
\text { EQUIPMENT }\end{array}$ & SPORTSWEAR & Underwater Wristwatch & 6 & 1.02 & 1.40 & 1. \\
\hline \multicolumn{7}{|c|}{ Single Underextension $[+--]$} \\
\hline $\begin{array}{l}\text { HOUSE } \\
\text { FURNISHINGS }\end{array}$ & FURNITURE & $\begin{array}{l}\text { Ashtray } \\
\text { Doorbell } \\
\text { Refrigerator }\end{array}$ & $\begin{array}{r}6 \\
10 \\
8\end{array}$ & $\begin{array}{l}0.72 \\
0.20 \\
1.60\end{array}$ & $\begin{array}{l}-0.72 \\
-1.77 \\
-0.50\end{array}$ & $\begin{array}{r}0.37 \\
-0.52 \\
0.65\end{array}$ \\
\hline FURNITURE & $\begin{array}{l}\text { HOUSE } \\
\text { FURNISHINGS }\end{array}$ & Park Bench & 7 & -0.62 & -1.50 & -1.12 \\
\hline HOBBIES & GAMES & $\begin{array}{l}\text { Beer Drinking } \\
\text { Eating Ice Cream } \\
\text { Washing Dishes }\end{array}$ & $\begin{array}{r}8 \\
10 \\
6\end{array}$ & $\begin{array}{r}0.85 \\
0.42 \\
-1.3\end{array}$ & $\begin{array}{l}-0.40 \\
-1.72 \\
-2.22\end{array}$ & $\begin{array}{r}0.30 \\
-0.17 \\
-1.47\end{array}$ \\
\hline GAMES & HOBBIES & Wrestling & 6 & 1.17 & 0.97 & 1.52 \\
\hline INSTRUMENTS & TOOLS & Door Key & 6 & -0.12 & -0.52 & -0.27 \\
\hline
\end{tabular}


APPENDIX A (Continued)

\begin{tabular}{|c|c|c|c|c|c|c|}
\hline Category A & Category B & Item & $N$ & A & B & Disj \\
\hline $\begin{array}{l}\text { KITCHEN } \\
\text { UTENSILS }\end{array}$ & $\begin{array}{l}\text { HOUSEHOLD } \\
\text { APPLIANCES }\end{array}$ & $\begin{array}{l}\text { Apron } \\
\text { Mat } \\
\text { Vegetable Rack }\end{array}$ & $\begin{array}{l}6 \\
7 \\
7\end{array}$ & $\begin{array}{r}0.12 \\
-0.80 \\
0.80\end{array}$ & $\begin{array}{l}-1.12 \\
-1.32 \\
-0.52\end{array}$ & $\begin{array}{r}-0.22 \\
-0.82 \\
0.37\end{array}$ \\
\hline $\begin{array}{l}\text { HOUSEHOLD } \\
\text { APPLIANCES }\end{array}$ & $\begin{array}{l}\text { KITCHEN } \\
\text { UTENSILS }\end{array}$ & $\begin{array}{l}\text { Electric Toothbrush } \\
\text { Iron } \\
\text { Television } \\
\text { Vacuum Cleaner }\end{array}$ & $\begin{array}{r}11 \\
7 \\
7 \\
8\end{array}$ & $\begin{array}{l}0.27 \\
1.55 \\
0.75 \\
1.90\end{array}$ & $\begin{array}{l}-2.37 \\
-1.60 \\
-2.00 \\
-1.65\end{array}$ & $\begin{array}{r}-0.20 \\
1.35 \\
0.12 \\
1.22\end{array}$ \\
\hline PETS & $\begin{array}{l}\text { FARMYARD } \\
\text { ANIMALS }\end{array}$ & $\begin{array}{l}\text { Camel } \\
\text { Circus Horse } \\
\text { Doberman Guard Dog } \\
\text { Guide Dog for the Blind } \\
\text { Husky in a Sled Team }\end{array}$ & $\begin{array}{r}6 \\
8 \\
7 \\
5 \\
15\end{array}$ & $\begin{array}{r}-1.20 \\
-0.40 \\
1.85 \\
1.77 \\
0.80\end{array}$ & $\begin{array}{l}-2.07 \\
-1.02 \\
-0.47 \\
-1.55 \\
-1.70\end{array}$ & $\begin{array}{r}-1.45 \\
-0.57 \\
1.62 \\
1.37 \\
-0.02\end{array}$ \\
\hline $\begin{array}{l}\text { FARMYARD } \\
\text { ANIMALS }\end{array}$ & PETS & $\begin{array}{l}\text { Robin } \\
\text { Spider }\end{array}$ & $\begin{array}{l}6 \\
7\end{array}$ & $\begin{array}{l}-0.05 \\
-0.02\end{array}$ & $\begin{array}{l}-1.05 \\
-1.32\end{array}$ & $\begin{array}{r}0.27 \\
-0.47\end{array}$ \\
\hline $\begin{array}{l}\text { SPORTS } \\
\text { EQUIPMENT }\end{array}$ & SPORTSWEAR & $\begin{array}{l}\text { Cheerleaders' Pompoms } \\
\text { Hoolahoop } \\
\text { Penalty Marker }\end{array}$ & $\begin{array}{r}6 \\
15 \\
11\end{array}$ & $\begin{array}{l}0.72 \\
1.00 \\
1.12\end{array}$ & $\begin{array}{l}-0.92 \\
-1.75 \\
-1.82\end{array}$ & $\begin{array}{r}-0.02 \\
0.07 \\
0.55\end{array}$ \\
\hline SPORTSWEAR & $\begin{array}{l}\text { SPORTS } \\
\text { EQUIPMENT }\end{array}$ & $\begin{array}{l}\text { Ballet Shoes } \\
\text { Sunglasses }\end{array}$ & $\begin{array}{l}6 \\
7\end{array}$ & $\begin{array}{l}1.15 \\
0.95\end{array}$ & $\begin{array}{r}0.95 \\
-0.25\end{array}$ & $\begin{array}{l}0.92 \\
0.17\end{array}$ \\
\hline VEGETABLES & FRUITS & $\begin{array}{l}\text { Garlic } \\
\text { Parsley } \\
\text { Pepper } \\
\text { Rice }\end{array}$ & $\begin{array}{l}6 \\
6 \\
6 \\
8\end{array}$ & $\begin{array}{r}-0.75 \\
0.65 \\
-0.72 \\
-0.32\end{array}$ & $\begin{array}{l}-1.95 \\
-1.97 \\
-1.85 \\
-2.07\end{array}$ & $\begin{array}{r}-0.67 \\
0.90 \\
-0.20 \\
-0.50\end{array}$ \\
\hline \multicolumn{7}{|c|}{ Overextensions $[--+]$} \\
\hline $\begin{array}{l}\text { HOUSE } \\
\text { FURNISHINGS }\end{array}$ & FURNITURE & Spice Rack & 5 & 0.55 & -1.07 & 0.95 \\
\hline INSTRUMENTS & TOOLS & $\begin{array}{l}\text { Meat Thermometer } \\
\text { Paper Clip } \\
\text { Pencil Eraser } \\
\text { Scotch Tape }\end{array}$ & $\begin{array}{l}5 \\
5 \\
9 \\
5\end{array}$ & $\begin{array}{r}1.52 \\
-0.42 \\
0.00 \\
-0.67\end{array}$ & $\begin{array}{r}0.20 \\
-0.20 \\
-0.17 \\
-0.45\end{array}$ & $\begin{array}{l}1.90 \\
0.12 \\
0.80 \\
0.05\end{array}$ \\
\hline $\begin{array}{l}\text { KITCHEN } \\
\text { UTENSILS }\end{array}$ & $\begin{array}{l}\text { HOUSEHOLD } \\
\text { APPLIANCES }\end{array}$ & Television & 5 & -2.00 & 0.75 & 0.12 \\
\hline PETS & $\begin{array}{l}\text { FARMYARD } \\
\text { ANIMALS }\end{array}$ & $\begin{array}{l}\text { Robin } \\
\text { Squirrel }\end{array}$ & $\begin{array}{l}7 \\
9\end{array}$ & $\begin{array}{l}-1.05 \\
-0.95\end{array}$ & $\begin{array}{l}-0.05 \\
-0.52\end{array}$ & $\begin{array}{r}0.27 \\
-0.05\end{array}$ \\
\hline $\begin{array}{l}\text { SPORTS } \\
\text { EQUIPMENT }\end{array}$ & SPORTSWEAR & Baseball Field & 6 & -0.62 & -2.22 & -0.52 \\
\hline VEGETABLES & FRUITS & $\begin{array}{l}\text { Acorn } \\
\text { Almond } \\
\text { Chili } \\
\text { Parsley }\end{array}$ & $\begin{array}{r}10 \\
10 \\
9 \\
7\end{array}$ & $\begin{array}{r}-1.60 \\
-1.62 \\
-0.37 \\
0.65\end{array}$ & $\begin{array}{l}-1.65 \\
-1.70 \\
-2.15 \\
-1.97\end{array}$ & $\begin{array}{r}-0.60 \\
-0.65 \\
0.22 \\
0.90\end{array}$ \\
\hline VEGETABLES & FRUITS & $\begin{array}{l}\text { Pepper } \\
\text { Rice } \\
\text { Wheat }\end{array}$ & $\begin{array}{r}10 \\
7 \\
6 \\
\end{array}$ & $\begin{array}{l}-0.72 \\
-0.32 \\
-1.05 \\
\end{array}$ & $\begin{array}{l}-1.85 \\
-2.07 \\
-2.15 \\
\end{array}$ & $\begin{array}{l}-0.20 \\
-0.50 \\
-0.75 \\
\end{array}$ \\
\hline
\end{tabular}

APPENDIX B

Items in Experiment 2 Overextended or Underextended with Respect to the Maximum Constituent $p[+]$ by at Least $.2[$ Diff $=$ Maximum $(A, B)-$ Disjunction]

\begin{tabular}{|c|c|c|c|c|c|c|}
\hline Category A & Category B & Item & A & B & Disj & Diff \\
\hline \multicolumn{7}{|c|}{ Underextension of Category $A$} \\
\hline HOUSE & FURNITURE & Ashtray & .7 & .3 & .25 & \\
\hline \multirow{3}{*}{ FURNISHINGS } & & Waste-Paper Basket & 1.0 & .5 & .6 & .4 \\
\hline & & Refrigerator & .9 & .7 & .58 & .32 \\
\hline & & Sink Unit & .9 & .6 & .6 & .3 \\
\hline
\end{tabular}


APPENDIX B (Continued)

\begin{tabular}{|c|c|c|c|c|c|c|}
\hline Category A & Category B & Item & A & B & Disj & Diff \\
\hline FURNITURE & $\begin{array}{l}\text { HOUSE } \\
\text { FURNISHINGS }\end{array}$ & Park Bench & .3 & .0 & .05 & .25 \\
\hline HOBBIES & GAMES & $\begin{array}{l}\text { Discus Throwing } \\
\text { Beer Drinking } \\
\text { Wrestling } \\
\text { Judo } \\
\text { Karate }\end{array}$ & $\begin{array}{l}1.0 \\
.87 \\
.9 \\
1.0 \\
1.0\end{array}$ & $\begin{array}{l}.78 \\
.2 \\
.6 \\
.7 \\
.7\end{array}$ & $\begin{array}{l}.7 \\
.58 \\
.63 \\
.8 \\
.8\end{array}$ & $\begin{array}{l}.3 \\
.29 \\
.27 \\
.2 \\
.2\end{array}$ \\
\hline PETS & $\begin{array}{l}\text { FARMYARD } \\
\text { ANIMALS }\end{array}$ & $\begin{array}{l}\text { Camel } \\
\text { Monkey }\end{array}$ & $\begin{array}{l}.4 \\
.5\end{array}$ & $\begin{array}{l}.0 \\
.0\end{array}$ & $\begin{array}{l}.1 \\
.25\end{array}$ & $\begin{array}{l}.3 \\
.25\end{array}$ \\
\hline $\begin{array}{l}\text { FARMYARD } \\
\text { ANIMALS }\end{array}$ & PETS & $\begin{array}{l}\text { Field Mouse } \\
\text { Rat }\end{array}$ & .7 & $\begin{array}{l}.1 \\
.5\end{array}$ & $\begin{array}{l}.4 \\
.4\end{array}$ & $\begin{array}{l}.3 \\
.3\end{array}$ \\
\hline SPICES & HERBS & Vanilla & .6 & .0 & .26 & .34 \\
\hline INSTRUMENTS & TOOLS & Bicycle Pump & 1.0 & .9 & .7 & .3 \\
\hline TOOLS & INSTRUMENTS & $\begin{array}{l}\text { Pencil Eraser } \\
\text { Computer } \\
\text { Spoon }\end{array}$ & $\begin{array}{l}.7 \\
.8 \\
.9\end{array}$ & $\begin{array}{l}.4 \\
.6 \\
.67\end{array}$ & $\begin{array}{l}.45 \\
.6 \\
.7\end{array}$ & $\begin{array}{l}.25 \\
.2 \\
.2\end{array}$ \\
\hline SPORTSWEAR & $\begin{array}{l}\text { SPORTS } \\
\text { EQUIPMENT }\end{array}$ & $\begin{array}{l}\text { Sunglasses } \\
\text { Bathing Costume }\end{array}$ & $\begin{array}{r}.4 \\
1.0\end{array}$ & $\begin{array}{l}.2 \\
.8\end{array}$ & $\begin{array}{l}.1 \\
.8\end{array}$ & $\begin{array}{l}.3 \\
.2\end{array}$ \\
\hline $\begin{array}{l}\text { SPORTS } \\
\text { EQUIPMENT }\end{array}$ & SPORTSWEAR & Linesman's Flag & 1.0 & .1 & .75 & .25 \\
\hline $\begin{array}{l}\text { HOUSEHOLD } \\
\text { APPLIANCES }\end{array}$ & $\begin{array}{l}\text { KITCHEN } \\
\text { UTENSILS }\end{array}$ & Electric Toothbrush & .8 & .0 & .55 & .25 \\
\hline FRUITS & VEGETABLES & $\begin{array}{l}\text { Elderberry } \\
\text { Overextensions }\end{array}$ & 1.0 & .0 & .8 & .2 \\
\hline PETS & $\begin{array}{l}\text { FARMYARD } \\
\text { ANIMALS }\end{array}$ & $\begin{array}{l}\text { Spider } \\
\text { Guide Dog for the Blind }\end{array}$ & .4 & $\begin{array}{l}.33 \\
.0\end{array}$ & $\begin{array}{l}.65 \\
.9\end{array}$ & $\begin{array}{l}-.25 \\
-.2\end{array}$ \\
\hline HERBS & SPICES & $\begin{array}{l}\text { Horseradish } \\
\text { Vinegar } \\
\text { Sesame Seeds } \\
\text { Monosodium Glutamate } \\
\text { Sugar }\end{array}$ & $\begin{array}{l}.4 \\
.0 \\
.4 \\
.1 \\
.0\end{array}$ & $\begin{array}{l}.2 \\
.1 \\
.33 \\
.11 \\
.0\end{array}$ & $\begin{array}{l}.7 \\
.35 \\
.63 \\
.33 \\
.2\end{array}$ & $\begin{array}{l}-.3 \\
-.25 \\
-.23 \\
-.22 \\
-.2\end{array}$ \\
\hline $\begin{array}{l}\text { KITCHEN } \\
\text { UTENSILS }\end{array}$ & $\begin{array}{l}\text { HOUSEHOLD } \\
\text { APPLIANCES }\end{array}$ & $\begin{array}{l}\text { Rubbish Bin } \\
\text { Cake Tin }\end{array}$ & $\begin{array}{l}.5 \\
.7\end{array}$ & $\begin{array}{l}.5 \\
.4\end{array}$ & $\begin{array}{l}.8 \\
.95\end{array}$ & $\begin{array}{l}-.3 \\
-.25\end{array}$ \\
\hline FRUITS & VEGETABLES & $\begin{array}{l}\text { Mushroom } \\
\text { Yam } \\
\text { Coconut } \\
\text { Garlic } \\
\text { Olive } \\
\text { Tomato } \\
\text { Root Ginger } \\
\text { Almond } \\
\text { Parsley } \\
\text { Broccoli } \\
\text { Green Pepper } \\
\text { Watercress }\end{array}$ & $\begin{array}{l}.0 \\
.43 \\
.7 \\
.1 \\
.5 \\
.7 \\
.0 \\
.2 \\
.0 \\
.0 \\
.3 \\
.0\end{array}$ & $\begin{array}{l}.5 \\
.67 \\
.0 \\
.2 \\
.1 \\
.7 \\
.3 \\
.1 \\
.2 \\
.8 \\
.6 \\
.6\end{array}$ & $\begin{array}{c}.9 \\
1.0 \\
1.0 \\
.5 \\
.8 \\
1.0 \\
.56 \\
.42 \\
.45 \\
1.0 \\
.8 \\
.8\end{array}$ & $\begin{array}{l}-.4 \\
-.33 \\
-.3 \\
-.3 \\
-.3 \\
-.3 \\
-.26 \\
-.22 \\
-.25 \\
-.2 \\
-.2 \\
-.2 \\
\end{array}$ \\
\hline
\end{tabular}

Note-Disj $=$ Disjunction. Diff $=\operatorname{Maximum}(\mathrm{A}, \mathrm{B})-$ Disjunction.

(Manuscript received August 3, 1987;

revision accepted for publication February 4,1988 .) 